\title{
PEMERIKSAAN IVA UNTUK DETEKSI DINI LESI PRA-KANKER DI MASA PANDEMI COVID-19 PADA MASYARAKAT MENDALO INDAH, JAMBI
}

\author{
Citra Maharani, Herlambang Herlambang, Rina Nofri Enis, Amelia Dwi Fitri, Erny \\ Kusdiyah, Huntari Harahap, Anggelia Puspasari, Asro Hayani Harahap \\ Fakultas Kedokteran dan IImu Kesehatan Universitas Jambi \\ Corresponding author email: citra_maharani@unja.ac.id
}

\begin{abstract}
Cervical cancer is the most common type of cancer in Indonensian women. The incidence of cervical cancer in Indonesia is $10.69 \%$, the second ranks after breast cancer. One of the efforts that can be done to reduce the incidence of cervical cancer is screening through the Visual Inspeksi Asam Asetat (IVA) method. The IVA examination method is simple but has high sensitivity for early detection of cervical pre-cancerous lesions. The current condition of the Covid-19 pandemic needs special attention, especially in providing optimal health services to the community. Therefore, this community service activity was carried out as a pro-active action to prevent cervical cancer through early detection of pre-cancerous lesions using the IVA method of reproductive age women in Mendalo Indah, Jambi. This community service activity applies health protocols to prevent the spread of Covid-19, such as using masks, applying physical distancing, using personal protective equipment for medical team and conducting screening rapid test for all teams and participants before start the activity. The IVA examination was take placed at the Poliklinik Pinang Masak Universitas Jambi and was attended by 5 participants. Providing education related to the importance of early detection of cervical cancer is also carried out to increase public knowledge and awareness. The results of the IVA examination of all participants were normal. All participants were enthusiastic during the counseling session.
\end{abstract}

Keywords: IVA examination, IVA test, precancerous lesions, cervical cancer

\section{ABSTRAK}

Kanker serviks merupakan jenis kanker utama yang paling banyak terjadi pada perempuan di Indonesia. Angka kejadian kanker serviks di Indonesia menempati posisi kedua setelah kanker payudara, yaitu sebesar 10,69\%. Salah satu upaya yang dapat dilakukan untuk mengurangi angka kejadian kanker serviks adalah penapisan melalui metode pemeriksaan Inspeksi Visual Asam Asetat (IVA). Metode pemeriksaan IVA sederhana namun memiliki sensitivitas tinggi untuk deteksi dini lesi pra-kanker serviks. Kondisi pandemi Covid-19 yang terjadi saat ini perlu mendapat perhatian khusus terutama dalam memberikan pelayanan kesehatan yang optimal kepada masyarakat. Oleh karena itu, kegiatan pengabdian kepada masyarakat ini dilakukan sebagai tindakan pro-aktif untuk mencegah kanker serviks melalui deteksi dini lesi pra-kanker menggunakan metode IVA pada perempuan usia produktif di kecamatan Mendalo Indah, Jambi. Kegiatan pengabdian kepada masyarakat ini menerapkan protokol kesehatan untuk mencegah penyebaran Covid19, seperti menggunakan masker, menerapkan physical distancing, penggunaan alat pelindung diri oleh tim medis dan melakukan skrining rapid test pada seluruh tim pengabdian dan peserta sebelum dimulainya 
kegiatan. Pemeriksaan IVA dilakukan di Poliklinik Pinang Masak Universitas Jambi dan diikuti oleh 5 orang peserta. Pemberian edukasi terkait pentingnya deteksi dini kanker serviks juga dilakukan untuk meningkatkan pengetahuan dan kesadaran masyarakat. Hasil pemeriksaan IVA seluruh peserta adalah normal. Peserta kegiatan berperan aktif saat pemberian edukasi oleh dokter ahli.

Kata kunci: pemeriksaan IVA, tes IVA, lesi pra-kanker, kanker serviks

\section{PENDAHULUAN}

Kanker serviks merupakan kanker terbanyak keempat yang terjadi pada perempuan. Berdasarkan data World Health Organization (WHO) angka kejadian kanker serviks di dunia pada tahun 2018 mencapai 570.000 perempuan dan sekitar 311.000 orang meninggal akibat penyakit ini. ${ }^{1}$ Data yang diperoleh dari Rumah Sakit Kanker Dharmais menunjukkan kejadian kanker serviks di Indonesia menduduki peringkat kedua terbanyak diantara kasus kanker lainnya dengan angka kejadian sebesar $10,69 \% .^{2}$

Pasien kanker serviks seringkali datang memeriksakan dirinya setelah timbul keluhan dan hasil pemeriksaan menunjukkan keganasan pada stadium lanjut. Hal ini bisa terjadi akibat masih kurangnya kesadaran masyarakat untuk melakukan pemeriksaan organ reproduksi secara berkala untuk deteksi dini kanker serviks. Kanker serviks dapat dicegah melalui deteksi dini kanker serviks menggunakan pap smear dan pemeriksaan Inspeksi Visual Asam Asetat (IVA). ${ }^{3}$

Pemeriksaan IVA merupakan pemeriksaan sederhana yang dapat dilakukan untuk deteksi dini kanker serviks dan memiliki beberapa keunggulan, antara lain mudah dilakukan oleh tenaga kesehatan, hasil pemeriksaan diperoleh segera dan menggunakan peralatan sederhana sehingga lebih ekonomis jika dibandingkan dengan pap smear. ${ }^{4}$ Pemeriksaan IVA juga memiliki sensitivitas yang tinggi untuk deteksi dini lesi pra-kanker serviks. ${ }^{5}$

Pada masa pandemi Covid-19 seperti saat ini, salah satu upaya yang dapat dilakukan oleh tenaga kesehatan untuk mengurangi risiko terjadinya kanker serviks yaitu berperan aktif dengan terjun ke masyarakat untuk melaksanakan deteksi dini pada organ reproduksi wanita melalui pemeriksaan IVA. Pemeriksaan dilakukan mengikuti protokol mitigasi Covid-19. Pemberian edukasi yang tepat mengenai kanker serviks juga dilakukan untuk meningkatkan kesadaran dan motivasi masyarakat untuk melakukan deteksi dini kanker serviks. Upaya ini dilakukan pada masyarakat kecamatan Mendalo Indah Jambi, dimana jumlah penduduk perempuan usia produktif di wilayah ini cukup banyak dengan berbagai latar belakang sosio ekonomi yang beragam. Hal ini menyebabkan perbedaan tingkat pengetahuan dan kesadaran masyarakat akan pentingnya deteksi dini untuk mencegah kanker serviks. 
METODE

Kegiatan pengabdian kepada masyarakat ini berlokasi di Polikilinik Pinang Masak Universitas Jambi. Sebelumnya tim pengabdian telah mengajukan perizinan kepada pihak Polikilinik selaku mitra kegiatan dan menyebarluaskan informasi kegiatan pemeriksaan IVA kepada masyarakat melalui media sosial.

Kegiatan pengabdian kepada masyarakat ini dilaksanakan dalam bentuk pemeriksaan IVA secara gratis serta pemberian edukasi pada sesi konseling setelah melakukan pemeriksaan. Kegiatan diikuti oleh 5 orang peserta. Seluruh tim pengabdian dan peserta kegiatan telah melakukan pemeriksaan rapid test Covid-19 sebelum kegiatan berlangsung dan dinyatakan non-reaktif.

\section{HASIL DAN PEMBAHASAN}

Kegiatan pengabdian kepada masyarakat ini menerapkan protokol kesehatan secara ketat mengingat kegiatan dilaksanakan pada masa pandemi Covid-19. Physical distancing juga diterapkan selama kegiatan berlangsung. Sebelum memasuki Poliklinik seluruh tim pengabdian dan peserta wajib mencuci tangan dan menggunakan masker selama kegiatan berlangsung. Seluruh tim medis yang bertugas juga dilengkapi dengan alat pelindung diri.

Kegiatan diawali dengan pemeriksaan rapid test Covid-19 kepada seluruh tim pengabdian dan calon peserta kegiatan. Peserta yang dapat mengikuti pemeriksaan IVA apabila bersedia melakukan rapid test sebelum pemeriksaan dan didapatkan hasilnya non-reaktif. Peserta dengan hasil rapid test non-reaktif sebanyak 5 orang. Seluruh peserta kegiatan termasuk dalam kategori perempuan usia produktif, merupakan civitas akademika Universitas Jambi dan warga masyarakat kecamatan Mendalo Indah, Jambi. Sebelum melakukan pemeriksaan IVA, dilakukan anamnesis mengenai riwayat kesehatan organ reproduksi pada seluruh peserta kegiatan oleh dokter umum.

Pemeriksaan IVA pada kegiatan pengabdian kepada masyarakat ini berlangsung selama sekitar 15 menit dan dikerjakan oleh dokter spesialis kandungan dan kebidanan yang kompeten. Hasil pemeriksaan pada seluruh peserta normal yaitu tidak terdapat perubahan warna berupa plak putih pada portio serviks setelah pemberian asam asetat $5 \%$. Setelah pemeriksaan IVA, kegiatan dilanjutkan dengan sesi konseling antara peserta kegiatan dengan dokter secara personal. Dokter pemeriksa terlebih dahulu menyampaikan hasil pemeriksaan IVA, kemudian dilanjutkan dengan sesi konseling dan edukasi. Materi edukasi yang diberikan pada kegiatan ini antara lain mengenai tanda dan gejala kanker serviks, pentingnya deteksi dini kanker, dan upaya pencegahan kanker melalui pola hidup bersih dan sehat. Dokter juga mengedukasi peserta agar melakukan pemeriksaan berkala organ reproduksi melalui pemeriksaan IVA atau pap smear.

Sesi konseling dan edukasi secara personal setelah pemeriksaan IVA menjadi keunggulan dalam kegiatan pengabdian kepada masyarakat ini. Peserta mendapat 
kesempatan untuk bertanya sebanyakbanyaknya kepada dokter ahli terkait kondisi kesehatan dirinya dan mendapatkan pengetahuan mengenai kanker serviks. Peserta kegiatan berperan aktif dan antusias bertanya saat mengikuti sesi konseling.

Terbatasnya jumlah peserta pada pemeriksaan IVA ini mungkin saja disebabkan karena kurangnya pengetahuan masyarakat akan pentingnya deteksi dini kanker serviks. Adanya kekhawatiran mengenai ketidak nyamanan saat pemeriksaan organ reproduksi wanita juga dapat mengurungkan niat masyarakat untuk melakukan pemeriksaan. Ditambah lagi kondisi pandemi Covid-19 saat ini menimbulkan keraguan masyarakat untuk mendatangi fasilitas kesehatan.

Kegiatan pengabdian kepada masyarakat berupa pemeriksaan IVA diharapkan dapat dilakukan rutin tiap tahunnya secara gratis, terutama di masa pandemi dengan mengikuti protokol kesehatan yang berlaku. Pemeriksaan IVA disertai pemberian edukasi terkait kanker serviks perlu dilakukan secara aktif oleh tenaga medis dengan mendatangi langsung masyarakat baik di kota dan di desa. Sesuai peraturan Menteri Kesehatan (2017) pemeriksaan IVA tidak hanya dilakukan di fasilitas kesehatan saja namun bisa dilaksanakan pada tempat-tempat yang memenuhi syarat untuk dilakukannya pemeriksaan. ${ }^{6}$ Melalui cara ini diharapkan semakin banyak masyarakat yang akan terdeteksi dan teredukasi sehingga dapat menekan morbiditas dan mortalitas akibat penyakit kanker serviks.

\section{KESIMPULAN}

Pemeriksaan IVA dilakukan dengan menerapkan protokol kesehatan sesuai arahan tim gugus Covid-19 dan hasil pemeriksaan IVA menunjukkan kesan normal pada seluruh peserta kegiatan. Peserta kegiatan juga menyambut antusias saat pemberian edukasi kanker serviks oleh dokter ahli. Kegiatan pemeriksaan IVA dan pemberian edukasi pada peserta berlangsung lancar dan tidak ada kendala yang berarti.

\section{DAFTAR PUSTAKA}

1. World Health Organization, 2021. Cervical cancer. Diakses Juni 2021 dari https://www.who.int/healthtopics/cervical-cancer\#tab=tab 1

2. Kemenkes RI, 2019. Beban kanker di Indonesia.

3. Notoatmodjo, S, 2010. Ilmu Perilaku Kesehatan. Jakarta : Rineka Cipta; Pedoman Pelayanan Medik Kanker Ginekologi, Kanker Serviks, ed-2,2011, hal 19-28.

4. World Health Organization, 2017. Cervical cancer screening and management of cervical pre-cancers; training of health staff in VIA, HPV detection test and cryotherapy. Diakses Juni 2021 dari https://cdn.who.int/media/docs/default-source/searo/tobacco/traineeshandbook.pdf?sfvrsn $=6778145 \mathrm{~d} 2$

5. Wiyono, S., Iskandar, T.M., Suprijono, 2008. Inspeksi visual asam asetat (IVA) untuk deteksi dini lesi prakanker serviks. Media Medika Indonesiana. 43(3):116-121.

6. Kementrian Kesehatan Republik Indonesia, 2017. Peraturan Menteri Kesehatan Republik Indonesia No. 29 Tahun 2014 tentang penanggulangan kanker payudara dan kanker leher rahim. Diakses Juni 2021

dar http://hukor.kemkes.go.id/uploads/produk_hukum/PMK_No._29_ttg_Penanggulangan_Kanker_Payu dara_dan_Kanker_Leher_Rahim_.pdf 
MEDIC, Volume 4, nomor 1, April 2021, Hal: 165-169 Citra Maharani, dkk. Pemeriksaan IVA...

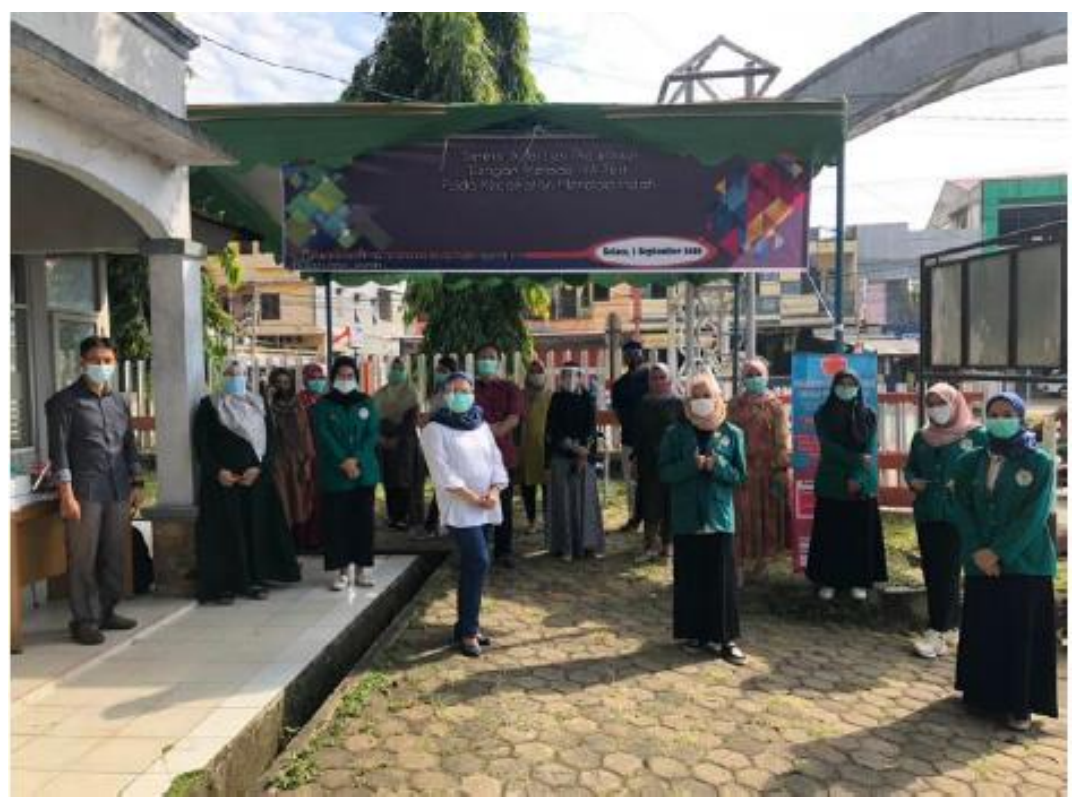

